\title{
Recruitment in epifaunal communities: an experimental test of the effects of species composition and age
}

\author{
H. Lindsay ${ }^{1}$, C. Todd $^{2}$, T. Fernandes ${ }^{3}$, M. Huxham ${ }^{3, *}$ \\ ${ }^{1}$ Royal Haskoning, 10 Bernard Street, Edinburgh EH6 6PP, UK \\ ${ }^{2}$ The Gatty Marine Laboratory, St Andrews University, St Andrews, Fife KY168LB, UK \\ ${ }^{3}$ School of Life Sciences, Napier University, 10 Colinton Road, Edinburgh EH10 5DT, UK
}

\begin{abstract}
A key prediction to emerge from community assembly models is that resistance to invasion increases as the community matures. Three epifaunal communities of differing age were developed upon artificial substrata in the Firth of Forth, Scotland, to examine whether community age influenced the rate of establishment of new recruits. Four repeat experiments assessed the numbers of species and individuals invading a controlled amount of free space in these communities. The oldest communities were invaded by the smallest mean number of species in each experiment although these differences were significant for only 1 experiment. Multiple regression showed that age was the most significant predictor variable of the percentage coverage of new species. Because there were no significant effects on communities only a few centimetres away, the mechanisms by which community age controlled invasion in these experiments operate over small spatial scales. These data support the prediction that older communities are more resistant to invasion, but only if the term invasion includes further recruitment of species already present in the community. However, the experimental design does not distinguish between the effects of age per se, and those of different assemblage sequences. As expected, species responded in different ways to community age, and species composition played an important role in determining the success of invasion.
\end{abstract}

KEY WORDS: Community · Age $\cdot$ Recruitment $\cdot$ Invasion $\cdot$ Assembly models $\cdot$ Successional theory

\section{INTRODUCTION}

How ecological communities assemble, and whether they follow certain 'assembly rules', have long been fundamental questions posed by ecologists. Community assembly models have in common the assumption that communities develop according to simple rules; successional models are perhaps the oldest and bestknown examples. Assembly rules have been defined as 'ecological restrictions on the observed patterns of species' presence or abundance that are based on the presence or abundance of one or more species or groups of species' (Wilson \& Gitay 1995).

Deterministic succession theories (such as the models summarized by Connell \& Slatyer 1977) describe the development of communities towards a single cli- max state, and a range of alternative models has been variously developed (Pimm 1982, Post \& Pimm 1983, Drake 1985, Drake et al. 1996). These often differ from deterministic models in important ways. For example, Diamond (1975) suggested that assembly processes can generate different final communities, and defined rules to predict likely and unlikely combinations of species. Final community composition may be contingent on the sequence of arrival of species. For example, Weatherby et al. (1998) showed that within experimental protist communities some species induce a change in community composition, but are rarely seen to persist and can therefore be thought of as 'catalyst' species.

One of the key predictions to emerge from most of these non-deterministic assembly models is that resis- 
tance to invasion increases as the community matures (Post 1983, Post \& Pimm 1983, Drake 1985, Kokkoris et al. 1999). This prediction is consistent with the models of succession described by Connell \& Slatyer (1977), and is thus one of the more robust predictions to arise from assembly theory. Following Diamond (1975), Belyea \& Lancaster (1999) inferred that the proportion of available resources consumed increases as species invade, and theoretically older communities should be more efficient and more difficult to invade. This appropriation of available resources and niche space is the mechanism underlying the increasing resistance to new recruitment in most models.

The main driving force in the development of epifaunal sessile communities is competition for primary space, which is often a limiting factor (Dayton 1971). Space is likely to constitute a limiting resource because of the minimum requirements for attachment, feeding and growth of sessile organisms and because these species cannot move: competition for space in sessile species can still be intense even when the resource (primary space) is not strictly limiting (that is, preempted) (Turner \& Todd 1993). As communities age, and the primary free space available for colonisation diminishes, community development can be regarded as a species-by-species replacement process that Greene \& Schoener (1982) likened to a lottery for living space. Here, we were not concerned with the relatively trivial prediction that a decrease in free space will result in a decrease in recruitment rates and the

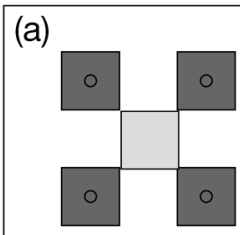

AGE 1

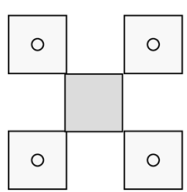

AGE 2

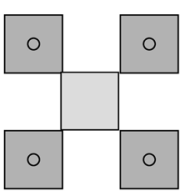

AGE 4

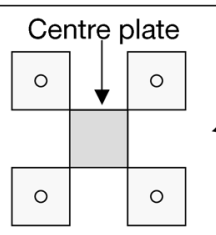

AGE 2

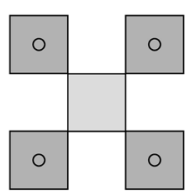

AGE 3

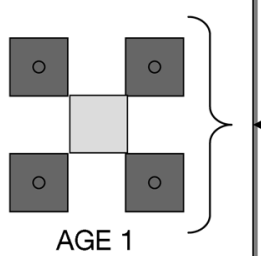
Board

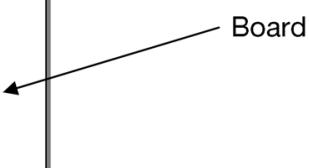

(b) Removable Plug

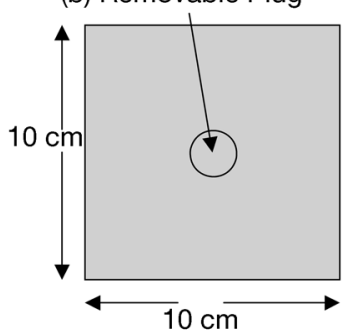

One group of four settlement plates, all of one age, with a centre plate

Fig. 1. (a) Example of a sampling board and the arrangement of settlement plate groups of 3 different ages, with the centre plate present in each group of plates; (b) individual settlement plate with plug detail effects of free space were therefore controlled between treatments.

The primary focus of the present study was to test the prediction from assembly theory that older communities are better able to resist invasion than younger communities, by quantifying the establishment of new recruits. The effects of particular species on recruitment rates were also investigated. Three epifaunal communities of differing ages were established in the Firth of Forth, Scotland, to allow tests of the null hypothesis that community age had no influence on the rate of invasion into that same community. The study area was specifically chosen to provide a sheltered, wave-protected location in an estuarine environment that would result in the development of relatively species-simple communities.

\section{MATERIALS AND METHODS}

The experiment was conducted at the small pleasure boat marina, Port Edgar (Firth of Forth, Scotland Ordnance Survey GR 115785), where salinities range from 25 to 33. Roughened polypropylene settlement plates $(10 \times 10 \mathrm{~cm})$ were used to allow the establishment of epifaunal communities. Plates were attached to 5 $(1.25 \times 2 \mathrm{~m})$ smooth polypropylene boards and the boards were suspended horizontally, facing the seabed, by chains beneath floating pontoons. The plates were therefore permanently submerged, faced downwards and were maintained in constant shade at a depth of $1 \mathrm{~m}$.

Each board was deployed at a different location around the marina (with a range of 6 to $71 \mathrm{~m}$ between boards). In May 1999, 40 plates were attached to the boards ( 2 groups of 4 plates were positioned close to each other on each board; Fig. 1a); these comprised the replicate plates within the oldest treatment. A second set of 40 plates was deployed in August 1999 in the same manner (middle treatment), and a third set in November 1999 (youngest treatment). Each treatment thus comprised 40 replicate plates, arranged in 10 groups of 4 , with 2 groups on each board (Fig. 1a). The boards were submerged and left unmanipulated until August 2000, therefore providing 3 different age treatments of 9,12 and 15 mo. The interim development of the different communities was monitored photographically every $2 \mathrm{wk}$ for the first 2 mo, and monthly thereafter. The 
spaces between the plates on the board were regularly cleaned of any settled organisms. Photographs were analysed using image-analysis tools and percentage cover was estimated for all organisms, and for the free space available for further colonisation. All taxa were identified to species level, with the exception of the 2 barnacle species present, Semibalanus balanoides (L.) and Balanus crenatus (Brug.). Due to the difficulties distinguishing between the 2 species when newly settled, these were analytically pooled as 'barnacles'.

Each settlement plate had a removable circular plug in the centre (Fig. 1b), made of the same roughened polypropylene as the rest of the plate, which served 2 purposes. First, when the plug was removed, cleaned and replaced it provided a controlled area of free space on each plate (therefore allowing comparisons between plates unconfounded by differences in free space). Second, the plug could be removed and sterilised (by immersion in boiling water for $10 \mathrm{~min}$ ) ensuring that biofilms of different ages did not influence the results. Biofilms can exert major influences on larval settlement in marine epifaunal communities on hard substrata (Wieczorek \& Todd 1997). Because biofilms of varying age may confound settlement experiments, we considered it essential here to control for this variable.

Plugs were removed from the plates, cleaned, sterilised and replaced into the plates in August 2000. Also, at this time, a new centre plate was attached in the middle of each plate group (Fig. 1a). This latter plate effectively provided a 'larger plug' within sameage plate groups. It was included to allow tests of the spatial extent of any constraints on invasion and recruitment and the independence of neighbouring plates, by allowing the detection of any effects of plate group on recruitment into the area in their centre. Plates were redeployed for a further colonization period of $2 \mathrm{wk}$, after which they were removed from the water and recruitment onto the plugs and the centre plates was quantified visually with a grid square and magnifying glass. Organisms were identified and their percentage covers, along with that of free space, were recorded; it was also noted whether organisms represented new recruitment or were derived from overgrowth from established residents. Percentage cover was recorded because it provided a readily quantifiable measure of space appropriation. It does not, however, allow comparison of relative numbers of individuals of different taxa because of their different sizes and growth rates at the field site. Plugs and centre plates were again cleaned, sterilised and replaced and the experiment was repeated a further 3 times, totalling 4 repeated invasion experiments (Expts 1 to 4 ).

Data analyses. The data for percentage free space remaining on plugs, numbers of new species and per- centage cover of new species recruiting to the plugs during the $2 \mathrm{wk}$ of each experiment were examined for normality and homoscedasticity and transformed where necessary. Where possible (that is, where the assumption of multivariate normality was reasonable) multivariate ANOVA (MANOVA) was used to test the effects of age (fixed factor), board (random factor), age $\times$ board and group (random factor nested in age and board) on each dependent variable across all 4 experiments. This is essentially a repeated measures design, using MANOVA as a robust test when sphericity cannot be assumed (Tabachnick \& Fidell 1989). Where multivariate normality could not be assumed, individual ANOVA analyses - with the same structure as the MANOVA tests-were conducted for each experiment. A similar approach was taken with data for the centre plates, using a 2-way model, with age (fixed) and board (random), as the factors. MANOVA and ANOVA tests were performed using Minitab 13 and SAS 8.2 software.

Any differences between treatments could result from one or more dominant species having a disproportionate effect at one age level. To test for the effects of age, whilst controlling for the effects of individual species, multiple regression (SAS 8.2 software) was used. For each of the 4 experiments, percentage cover of newly recruited species on the plugs (dependent) was analysed in relation to multiple independents: (1) percentage cover of the species present on the surrounding plates, and (2) community age. Age was entered in the regression analyses as a 'dummy' value. The best models were chosen by comparing the outputs of both stepwise and all subsets regression, using Mallow's Cp statistic, and the variance inflation factor (VIF) as a test of multicollinearity (i.e. multicorrelation).

\section{RESULTS}

The use of plugs provided equal areas of free space within the communities of different age and allowed subsequent comparisons of recruitment that were not confounded by differences in free space. It was possible, however, that differing rates of overgrowth from organisms already established on the plates could nullify this design feature, so it was important to also assess the amount of free space remaining by the end of each experiment. The mean amount of free space remaining on the plugs varied from $<40 \%$ to nearly $90 \%$ (Fig. 2), with the latter for Expt 1 possibly reflecting a relative paucity of settling larvae in the water column during this time. The mean percentage free space on the intermediate-aged plugs was significantly higher than that on the oldest and youngest 


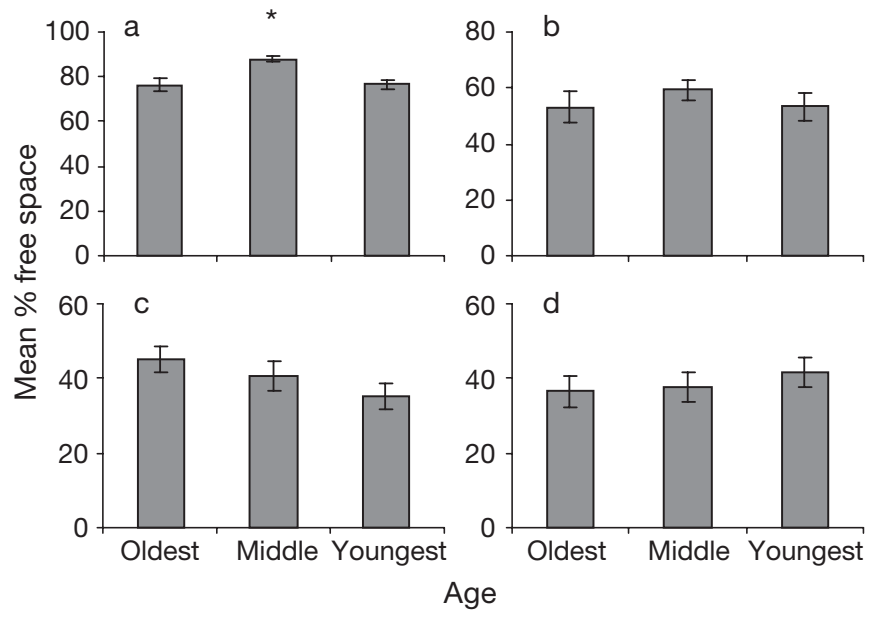

Fig. 2. Mean $( \pm \mathrm{SE})$ percentage freespace remaining for each repeat experiment $(\mathrm{a}-\mathrm{d})$ on different age plates; *: treatment significantly different $(p<0.05)$ from others

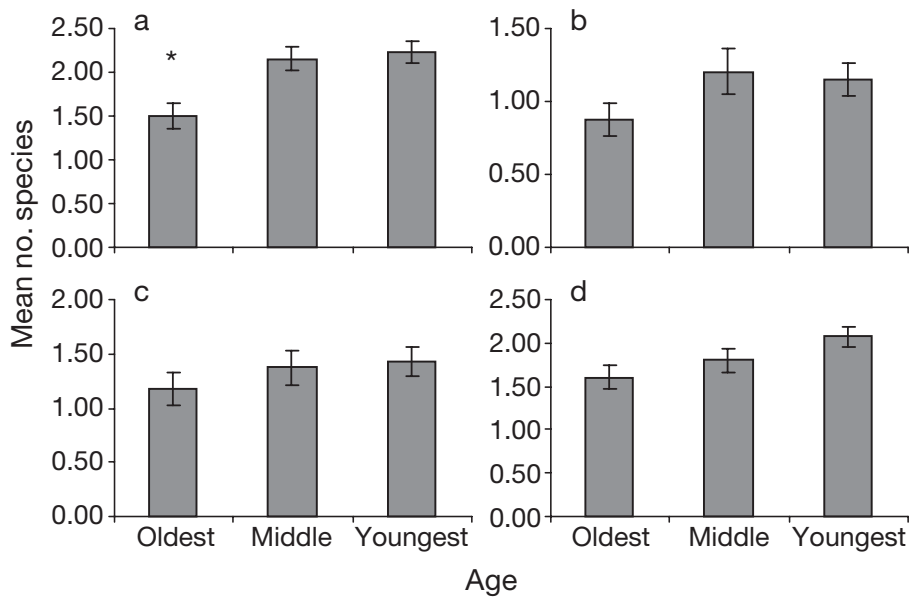

Fig. 3. Mean $( \pm \mathrm{SE})$ number of taxa recruiting onto the plug area during each repeat experiment $(\mathrm{a}-\mathrm{d})$ on different age plates; *: treatment significantly different $(p<0.05)$ from others

treatments at the end of Expt 1; none of the other 3 experiments showed significant within-experiment differences (Fig. 2).

All 4 experiments showed the same pattern of the lowest mean number of species recruiting to plugs in the oldest treatment (Fig. 3). These data did not conform to multivariate normality even after transformation, hence 4 separate ANOVAs were undertaken, 1 for each experiment. Age was significant in Expt 1 (Table 1) but non-significant for all other experiments, as were all the other factors. Taking the experiments together, the binomial probability of finding by chance the lowest recruitment to the oldest treatment in each experiment is $<0.02$.
There were no significant effects of age on mean percentage free space, mean number of species or mean percentage coverage of any particular species between the centre plates. These results demonstrated the statistical independence of plates within groups, and also the limited spatial extent of any influences of the surrounding community on recruitment. No significant differences were found in any tests between groups within boards-hence recruitment patterns were similar at scales of 0.5 to $1.0 \mathrm{~m}$. Significant effects were found between boards, showing that recruitment varied at scales of 6 to $71 \mathrm{~m}$.

The communities comprised a total of 23 taxa establishing into the plug areas during the 4 repeat experiments. Only 5 taxa-barnacles, the erect bryozoan Scrupocellaria scruposa, the tubeworm Pomatoceros lamarckii, the bivalve Mytilus edulis and the sheet-like bryozoan Electra pilosa-were newly recruited; the remainder colonized plugs by overgrowth from the surrounding community.

Table 1. ANOVA results for number of new species recruiting to plugs in Expt 1

\begin{tabular}{|lrccc|}
\hline Source & df & Adj MS & $F$ & $\mathrm{p}$ \\
\hline Age & 2 & 6.37 & 6.57 & 0.021 \\
Board & 4 & 1.64 & 1.69 & 0.244 \\
Age $\times$ Board & 8 & 0.97 & 1.17 & 0.377 \\
Group (age board) & 15 & 0.83 & 1.52 & 0.116 \\
Error & 89 & 0.56 & & \\
Total & 118 & & & \\
\hline
\end{tabular}

Table 2. MANOVA test results on percentage cover of 3 of the 5 species recruiting from the plankton onto the plugs. Independent variables were transformed percentage cover of each taxon in each of 4 experiments. Test criterion is Wilks' lambda. Barnacles comprise of Semibalanus balanoides and Balanus crenatus

\begin{tabular}{|lrccc}
\hline Taxon/Source & df & Statistic & $F$ & $\mathrm{p}$ \\
\hline Barnacles & & & & \\
Age & 8,10 & 0.042 & 4.9 & 0.011 \\
Board & 16,15 & 0.041 & 1.8 & 0.125 \\
Age $\times$ Board & 32,322 & 0.738 & 0.9 & 0.680 \\
Group (age board) & 60,341 & 0.542 & 1.0 & 0.548 \\
Scrupocellaria scruposa & & & & \\
Age & 8,10 & 0.064 & 3.7 & 0.029 \\
Board & 16,15 & 0.007 & 3.9 & 0.006 \\
Age $\times$ Board & 32,322 & 0.723 & 0.9 & 0.582 \\
Group (age board) & 60,341 & 0.541 & 1.0 & 0.543 \\
Pomatoceros lamarckii & & & & \\
Age & 8,10 & 0.072 & 3.4 & 0.036 \\
Board & 16,15 & 0.032 & 2.1 & 0.085 \\
Age $\times$ Board & 32,322 & 0.616 & 1.4 & 0.073 \\
Group (age board) & 60,341 & 0.582 & 0.8 & 0.782 \\
\hline
\end{tabular}



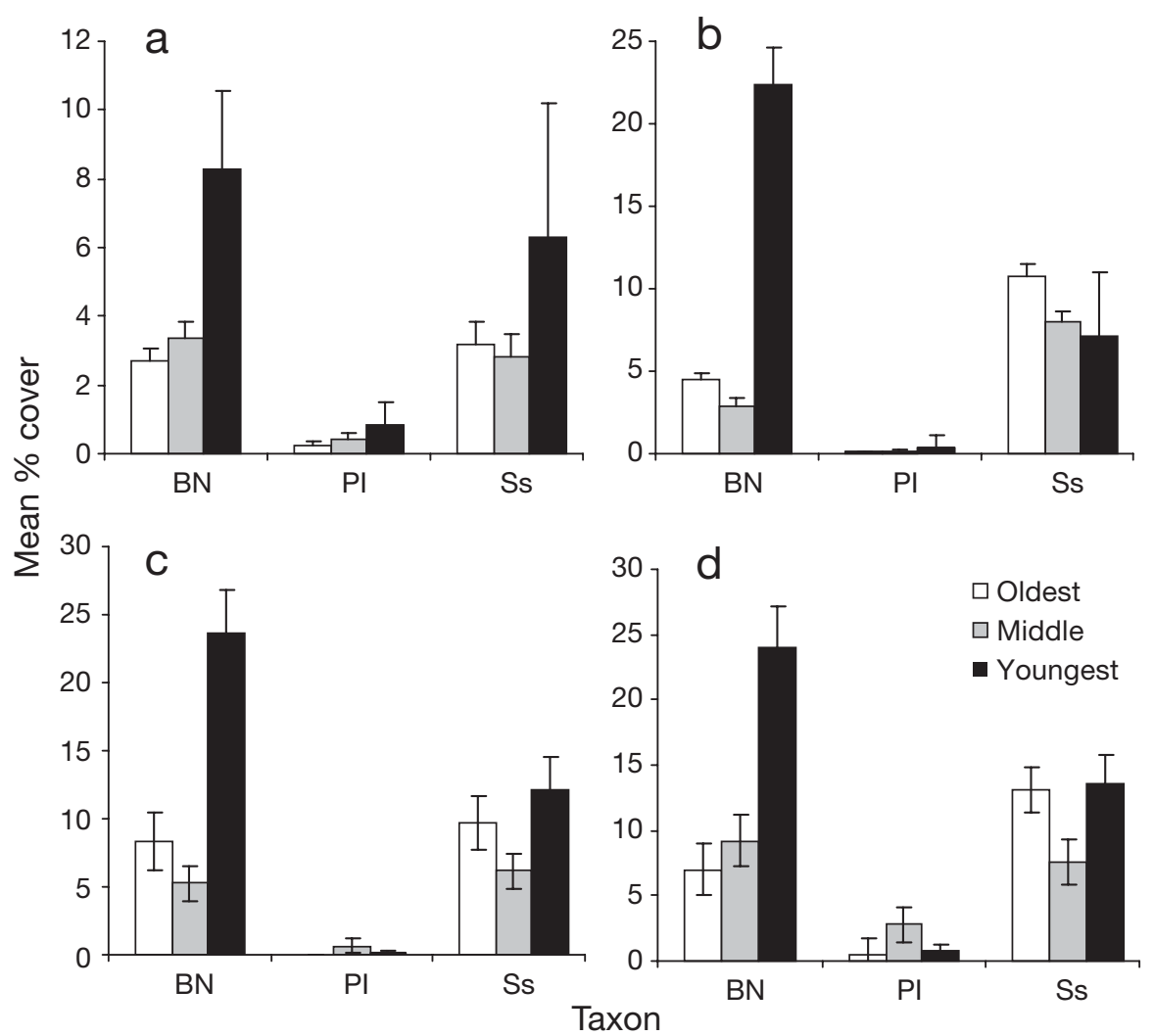

Fig. 4. Mean percentage cover $( \pm \mathrm{SE})$ of the 3 dominant newly recruited taxa during repeat experiments (a-d). BN: barnacles (Balanus crenatus and Semibalanus balanoides; Pl: Pomatoceros lamarckii Ss: Scrupocellaria scruposa

There was dense recruitment of barnacles onto the plates during all 4 experiments, with all of them showing the greatest recruitment to the youngest treatment (Fig. 4). Scrupocellaria scruposa was the second most common species. During all repeat experiments $S$. scruposa recruited in large numbers into the youngest community. The overall pattern for this species was one of most recruitment to the youngest, and the least to the intermediate age community, although this was not represented in Expt 2 when the oldest community showed highest recruitment. Pomatoceros lamarckii recruited in small numbers in all experiments, and in each one showed the lowest recruitment to the oldest age communities (Fig. 4). Mytilus edulis did not recruit during Expts 1 to 3. A few individuals established themselves during Expt 4 into both the oldest and youngest communities. Electra pilosa showed low levels of recruitment throughout Expts 1 and 3. Expt 1 showed little recruitment to the intermediate age community, and Expt 4 showed new E. pilosa recruitment to the youngest community.

MANOVA tests were undertaken for barnacle, Scrupocellaria scruposa and Pomatoceros lamarckii recruitment; data for Mytilus edulis and Electra pilosa, the other 2 recruiting taxa, could not be appropriately transformed (mainly because of the many zero counts). Age was a significant factor in each of these tests (Table 2).

Multiple regression was applied in the assessment of the effects on recruitment of community age, whilst still controlling for, and including, the effects of the various previously established species surrounding the plugs. All significant regression analyses for the 4 experiments are presented in Table 3. No values of VIF exceeded 2, indicating that interpretation is not compromised by multicollinearity (Zar 1999). Models chosen were those that minimised the $\mathrm{Cp}$ value whilst maximising adjusted $\mathrm{r}^{2}$ and included only significant or near-significant variables. The 4 taxa showing significant effects are considered separately below.

\section{Barnacles}

Age was the most significant factor influencing barnacle recruitment in all 4 experiments, with lower numbers recruiting to older communities. All repeats, except Expt 2, showed that previously established barnacles surrounding the plug exerted a positive (facilitatory) influence upon recruitment. All of the experiments also showed Scrupocellaria scruposa to be a facilitatory influence on new barnacle recruitment. For Expts 1 and 3 the colonial ascidians Botryllus schlosseri and Botrylloides leachi appeared to facilitate barnacle recruitment, and the same extended to Bugula sp. for Expts 2 and 4.

\section{Scrupocellaria scruposa}

Scrupocellaria scruposa showed mixed results, and for Expt 3 the regression was non significant. The significant outcomes for the remaining experiments were contradictory. Established S. scruposa exerted a positive influence on new $S$. scruposa recruitment to plugs for Expts 2 and 4 but had no influence during Expt 1. The presence of adult Mytilus edulis had a negative influence for Expts 2 and 4 but was non significant for Expts 1 and 3. Age of community and the presence of Electra pilosa and Balanus crenatus were all facilitatory factors on new recruitment of $S$. scruposa for Expt 4. 
Table 3. Results of multiple regression analyses on percentage coverage of settling species against percentage coverage of adults, present on the surrounding plate, as predictors. Results for each repeat experiment are shown separately. Numbers in parentheses are regression coefficients

\begin{tabular}{|c|c|c|c|c|c|}
\hline Expt & Dependent species & Predictor variable & Predictor $\mathrm{p}$ value & Adjusted $\mathrm{R}^{2}$ & Overall $\mathrm{p}$ value \\
\hline \multirow[t]{2}{*}{1} & Barnacles & $\begin{array}{l}\text { Age }(-0.046) \\
\text { Balanus crenatus }(0.122) \\
\text { Colonial ascidians }(0.08) \\
\text { Scrupocellaria scruposa }(0.165)\end{array}$ & $\begin{array}{r}0.001 \\
0.002 \\
0.022 \\
<0.001\end{array}$ & 0.400 & $<0.001$ \\
\hline & $\begin{array}{l}\text { S. scruposa } \\
\text { Mytilus edulis }\end{array}$ & $\begin{array}{l}\text { Age }(-0.012) \\
\text { Age }(-0.028) \\
\text { B. crenatus }(0.074) \\
\text { M. edulis }(-0.132) \\
\text { Bugula sp. }(-0.233) \\
\text { Ciona intestinalis }(-0.089)\end{array}$ & $\begin{array}{l}0.003 \\
0.016 \\
0.046 \\
0.002 \\
0.004 \\
0.101\end{array}$ & $\begin{array}{l}0.069 \\
0.383\end{array}$ & $\begin{array}{r}0.003 \\
<0.001\end{array}$ \\
\hline \multirow[t]{2}{*}{2} & Barnacles & $\begin{array}{l}\text { Age }(-0.072) \\
\text { S. scruposa }(0.251)\end{array}$ & $\begin{array}{r}<0.001 \\
0.003\end{array}$ & 0.236 & $<0.001$ \\
\hline & S. scruposa & $\begin{array}{l}\text { M. edulis }(-0.137) \\
\text { S. scruposa }(0.276)\end{array}$ & $\begin{array}{l}0.047 \\
0.006\end{array}$ & 0.081 & 0.003 \\
\hline \multirow[t]{2}{*}{3} & Barnacles & $\begin{array}{l}\text { Age }(-0.060) \\
\text { B. crenatus }(0.37) \\
\text { Colonial ascidians }(0.21) \\
\text { S. scruposa }(0.434)\end{array}$ & $\begin{array}{l}0.028 \\
0.001 \\
0.042 \\
0.001\end{array}$ & 0.245 & $<0.001$ \\
\hline & P. lamarckii & Tunicates $(0.051)$ & 0.033 & 0.031 & 0.033 \\
\hline \multirow[t]{3}{*}{4} & Barnacles & $\begin{array}{l}\text { Age }(-0.118) \\
\text { B. crenatus }(0.289) \\
\text { Bugula sp. }(0.288) \\
\text { S. scruposa }(0.258)\end{array}$ & $\begin{array}{r}<0.001 \\
0.002 \\
0.093 \\
0.024\end{array}$ & 0.304 & $<0.001$ \\
\hline & Pomatoceras lamarckii & P. lamarckii (0.156) & 0.012 & 0.046 & 0.012 \\
\hline & S. scruposa & $\begin{array}{l}\text { M. edulis }(-0.297) \\
\text { B. crenatus }(0.182) \\
\text { Age }(0.055) \\
\text { S. scruposa }(0.098)\end{array}$ & $\begin{array}{r}<0.001 \\
0.035 \\
0.021 \\
<0.001\end{array}$ & 0.378 & 0.001 \\
\hline
\end{tabular}

\section{Mytilus edulis}

Age was a significant (negative) influence on Mytilus edulis recruitment in Expt 1 only (Table 3). Other negative independents included established mussels surrounding the plugs, in addition to Bugula sp., and the solitary ascidian Ciona intestinalis. The only positive factor influencing new $M$. edulis recruitment was, again, the presence of surrounding barnacles.

\section{Pomatoceros lamarckii}

Significant results were recorded for Pomatoceros lamarcki in Expts 3 and 4. The only significant influence on $P$. lamarckii recruitment in Expt 3 was the ascidian grouping, comprising species such as Ascidiella scabra. Adult P. lamarckii in Expt 4 exerted a facilitatory influence on new recruitment of $P$. lamarckii to the plugs.

\section{DISCUSSION}

Our primary objective was to carry out a test of the prediction, from the assembly theory, that communities become more resistant to invasion as they age. We can show qualified support for this prediction; there was a persistent pattern of fewer individuals and species recruiting to older communities. This pattern was not the product simply of a lack of space in older communities. All replicates, regardless of age, offered the same amount of free space for settlement and recruitment at the start of each 2 wk experiment. Furthermore, the analysis of free space on the plugs at the conclusion of each experiment showed that the percentage of space overgrown by surrounding resident species was not significantly greater for the older treatments. The influence of community age was also not disproportionately attributable to one or a few dominant species characteristic of the older communities. Regression analyses indicate that age was the most important independent predictor of recruitment suc- 
cess, and that age can be genuinely regarded as a community level attribute at this spatial scale.

However, 3 important caveats are necessary in qualifying our interpretation of the results in terms of assembly theory. First, this study involved quantification of the percentage area recruitment of organisms to communities in which their species were already present; assembly theory generally has been applied to the invasion of entirely new species. Second, 'age' may be confounded with 'assembly sequence' in our study. Because plugs of different ages needed to be exposed to the same potential pool of settling organisms, recruitment was recorded at the same times. This meant that the age treatments also differed in the times of year that they were first established, and hence potentially in the assembly dynamics that they had experienced. An alternative design, establishing treatments at the same time and then exposing them to invasion at different subsequent times, was rejected because the pool of potential settlers would be different. These effects would also be confounded in natural communities. All plates were left for the duration of at least 1 peak settlement period (spring and early summer) and all age treatments contained the same species (although in different proportions). Hence differences were not due to the presence or absence of a key species in a particular age treatment. However, it is important to emphasize that age differences in these experiments (and indeed in most natural communities) imply potential differences in assembly sequences as well as just in time since establishment. Third, there were differences in responses among the various species treated as independents.

The prediction that resistance to invasion increases as the community matures is one of the most robust to arise from general assembly theory (Post 1983, Post \& Pimm 1983, Drake 1985, Luh \& Pimm 1993, Kokkoris et al. 1999). There is, however, some ambiguity in the literature regarding 'invasion' during assembly. Whilst some observers (e.g. Sutherland \& Karlson 1977, Weiher \& Keddy 1995, Lockwood et al.1997) have included individuals of resident species as 'invaders', others have considered only novel species. For example, the models developed by Luh \& Pimm (1993) ignored the quantitative aspects of population dynamics by focusing only upon the presence or absence of a species.

Because there were no novel species that recruited during the present experimental fortnights, here one cannot consider 'invasion' or 'invasibility' if these terms are defined to refer to new species only. However, community assembly clearly depends on the dynamics of species' turnover within communities, including the processes that lead to the eventual replacement or extinction of resident species. In most Lotka-Volterra based models, these dynamics are rep- resented by the $a_{i j}$ terms, showing the effects of the $j$ th species on the growth dynamics of the $i$ th species. Here, the focus was not on growth as such (because most of the individuals will have immigrated as planktonic larvae from communities, remote from the individual plates). Rather, the focus of interest was the influence of established residents on subsequent recruitment. Functionally, this will be similar to growth in the usual models; if a species cannot colonise free space, or secondary space, then eventually it will become extinct in the community.

Although age can be regarded as a community level attribute in this study, its effects are manifest only on the small $(\mathrm{cm})$ scale represented by the central plugs. The central plate within the different age sets showed no significant differences for new species numbers. Hence, whatever the biological mechanisms controlling recruitment to the plugs, they did not influence recruitment a few centimetres away.

Increased resistance to invasion is consistent with Connell \& Slatyer's (1977) facilitation (at least towards the end of succession) and tolerance models of succession, and these models can effectively describe how colonists eventually come to 'oust' or replace earlier species. As such, the processes of local extinction, rather than initial species invasion, are central to the assumptions and predictions of these models. The facilitation model assumes that only species that have 'early successional' characteristics are able to colonise new free space. These early species then modify the environment to render it more suitable for later species to invade. In the tolerance model, succession leads to a community comprising species most efficient in exploiting the available resources, and the sequence of species is determined solely by their life-history characteristics. Incumbent resident species do not have a facilitatory effect in the tolerance model and species that appear later may simply be those that arrived early and then grew slowly. In both models, early successional species are excluded from re-invading older communities, and overall diversity declines after reaching a maximum at some mid-successional juncture.

The present results provide some support for both the tolerance and facilitation models of succession. Such ambiguity is common; marine epifaunal assemblages have often been considered as not conforming to any of the classical models (e.g. Sutherland \& Karlson 1977, Turner \& Todd 1993). Greene \& Schoener (1982), for example, considered epifaunal species assembly to be largely the product of the probabilities of species arrival and extinction, and likened these to a 'fixed' lottery. Here, new species that settled into free space (and that initially settled onto the plates) were largely those with 'early successional' characteristics (e.g. barnacles), and 
older communities were more resistant to settlement by those species, and especially by barnacles. A different approach was adopted by Weiher \& Keddy (1995), who discussed community assembly as the progression of an originally rich species pool through one or more environmental 'filters', which select the final, and relatively species-poor, community. Our results provide indicative evidence for what some of these 'filters' may be in this particular habitat.

The most obvious, and frequently cited, 'filter' that could preclude settlement and recruitment is aggressive competition for space. Turner \& Todd (1993) suggested that primary space is likely to constitute a limiting resource to most (sessile) taxa in epifaunal communities if only because of organisms' minimum requirements for attachment, feeding and growth. Stachowicz et al. (1999) found that invasion resistance increased with increasing species richness, and similarly suggested that a simple lack of free space in species-rich epifaunal communities would reduce settlement rates. Because the present experiments specifically controlled for free space as a limiting factor, other factors must be operating here. Osman \& Whitlatch (1995) specifically investigated the influence of resident adult ascidians on larval settlement. They concluded that the most likely effect of residents was the usurpage of available primary substratum, but also that residents can prey on settling larvae, influence settling larvae with biochemical cues (either positively or negatively) and have the potential to overgrow newly attached individuals.

Other 'filters' that may be influencing settlement and hence recruitment rates, are substratum- and/or organism-associated biochemical cues, and these can be either facilitatory or inhibitory. Larvae of most fouling organisms (including barnacles and tubeworms, which were prominent here) attach more readily to biofilmed surfaces than to clean, non-biofilmed surfaces (e.g. Brancato \& Woollacott 1982, Hills \& Thomason 1996, Wieczorek et al. 1996, Wieczorek \& Todd 1997, Hamer et al. 2001). This indicates a general pattern of facilitation by bacterial biofilms, although negative effects have often been reported (e.g. Wieczorek \& Todd 1997). Our plugs were sterilised to ensure that biofilm age was consistent, hence differences between treatments were unlikely to be due to different biofilms on the plugs. However, differences in the biochemical cues being released by the communities surrounding the free space may well have influenced our results.

A third potential 'filter' is the physical effect of residents influencing local hydrodynamics and larval supply to the substratum (see Thomason et al. 1998), and of community residents directly consuming or destroying larvae. For example, adult Semibalanus balanoides may exert a strong inhibitory influence on barnacle recruitment partly by ingesting and damaging larvae (Berlow \& Navarrate 1997).

Our communities were, as expected, relatively species-poor, but previous microcosm and computer modelling experiments have used similar, or even simpler, species pools of potential colonists (Pimm 1982, Post \& Pimm 1983, Drake 1985, Drake et al. 1996). These latter models suggest that the resources liberated by the mortality of the dominant species are key to the successful establishment of subordinate species. Invading species must be able to rapidly colonise free space quicker than the adjacent established organisms (Dial \& Roughgarden 1998).

The overriding pattern seen here was one of community resistance to invasion increasing with age. Significantly lower mean numbers of species settled on the oldest treatment plates in Expt 1 and this pattern was consistent for the 4 experiments. However, there was considerable interspecific variation. The dominant species recruiting were Semibalanus balanoides and Balanus crenatus, primarily because of their strongly seasonal larval availability at the time of plug clearing. Community age negatively influenced barnacle recruitment in all 4 experiments. Although age emerged from the multiple regression analysis as the most significant factor influencing new larval settlement it was not the only significant influence. Adult barnacles surrounding the plug showed a positive influence on larval recruitment of other barnacles, as did Bugula sp. and Scrupocellaria scruposa. Barnacles and tubeworms tend to attach more readily in the presence of established conspecifics (e.g. Knight-Jones 1953), leading to clumped (gregarious) distributions, although some studies show negative effects of conspecifics (e.g. Navarrete \& Wieters 2000).

Results for other species were not as clear. For Scrupocellaria scruposa, community age had a significant effect overall (Table 2) but this was positive in Expt 4. Adult S. scruposa themselves showed a positive influence on new settlement during Expts 2 and 4. Mytilus edulis negatively affected S. scruposa settlement for Expts 2 and 4, and this was perhaps linked to adult $S$. scruposa not usually being abundant in welldeveloped assemblages dominated by $M$. edulis. Age also had a significant effect on Pomatoceros lamarckii recruitment (Table 2), with lowest numbers recruiting to the oldest communities. The other quantified recruiting species ( $M$. edulis and Electra pilosa) did so at very low percentage covers, and thus provide only weak statistical tests.

Overall, the 4 repeat experiments confirmed the importance of community age as a determinant of invasion resistance, and as an emergent property of these species-poor communities. But the effects of community age on new recruitment differed markedly accord- 
ing to species, despite the early stages of community development seemingly being consistent with the tolerance and facilitation models. Invasion resistance was also shown to operate on small spatial scales because new recruitment to the centre plates showed no significant responses to surrounding community age.

Acknowledgements. We thank the management at Port Edgar Marina for allowing the use of their facilities. S. Bonnellie provided statistical advice, and the manuscript was much improved after comments from 3 anonymous referees. H.L. received a grant from Napier University.

\section{LITERATURE CITED}

Belyea LR, Lancaster J (1999) Assembly rules within a contingent ecology. Oikos 86:402-416

Berlow EL, Navarrete SA (1997) Spatial and temporal variation in rocky intertidal community organization: lessons from repeating field experiments. J Exp Mar Biol Ecol 214: 195-229

Brancato MS, Woollacott RM (1982) Effect of microbial films on settlement of bryozoan larvae (Bugula simplex, B. stolonifera and B. turrita). Mar Biol 71:51-56

Connell JH, Slatyer RO (1977) Mechanisms of succession in natural communities and their role in community stability and organisation. Am Nat 111:1119-1144

Dayton PK (1971) Competition, disturbance, and community organization: the provision and subsequent utilization of space in a rocky intertidal community. Ecol Monogr 41: 351-389

Dial R, Roughgarden J (1998) Theory of marine communities: the intermediate disturbance hypothesis. Ecology 79: 1412-1424

Diamond JM (1975) Ecology and evolution of communities. Harvard University Press, Cambridge, MA

Drake JA (1985) Some theoretical and empirical explorations of structure in food webs. PhD dissertation, Purdue University, West Lafayette, IN

Drake JA, Huxel GR, Hewitt CL (1996) Microcosms as models for generating and testing community theory. Ecology 77 : 670-677

Greene CH, Schoener A (1982) Succession on marine hard substrata: a fixed lottery. Oecologia 55:289-297

Hamer JP, Walker G, Latchford JW (2001) Settlement of Pomatoceros lamarkii (Serpulidae) larvae on biofilmed surfaces and the effect of aerial drying. J Exp Mar Biol Ecol 260:113-131

Hills JM, Thomason JC (1996) A multi-scale analysis of settlement density and pattern dynamics of the barnacle Semibalanus balanoides. Mar Ecol Prog Ser 138:103-115

Knight-Jones EW (1953) Laboratory experiments on gregariousness during settling in Balanus balanoides and other barnacles. J Exp Biol 30:584-598

Editorial responsibility: Howard I. Browman (Associate Editor-in-Chief), Storebø, Norway
Kokkoris GD, Troumbis AY, Lawton JH (1999) Patterns of species interaction strength in assembled theoretical competition communities. Ecol Lett 2:70-74

Lockwood JL, Powell RD, Nott MP, Pimm SL (1997) Assembling ecological communities in time and space. Oikos 80: 549-553

Luh HK, Pimm SL (1993) The assembly of ecological communities - a minimalist approach. J Anim Ecol 62:749-765

Navarrete SA, Wieters EA (2000) Variation in barnacle recruitment over small scales: larval predation by adults and maintenance of community pattern. J Exp Mar Biol Ecol 253:131-148

Osman RW, Whitlatch RB (1995) The influence of resident adults on recruitment-a comparison to settlement. J Exp Mar Biol Ecol 190:169-198

Pimm S (1982) Food webs. Chapman \& Hall, London

Post WM, Pimm S (1983) Community assembly and food web stability. Math Biosci 64:169-192

Post WM (1983) Dynamic patterns of randomly assembled food webs. Current trends in food web theory. Report on a food web workshop. Oak Ridge National Laboratory, Oak Ridge, TN

Stachowicz JJ, Whitlatch RB, Osman RW (1999) Species diversity and invasion resistance in a marine ecosystem. Science 286:1577-1579

Sutherland JP, Karlson RH (1977) Development and stability of the fouling community at Beaufort, North Carolina. Ecol Monogr 47:425-446

Tabachnick BG, Fidell LS (1989) Using multivariate statistics. Harper Collins, New York

Thomason JC, Hills JM, Clare AS, Neville A, Richardson M (1998). Hydrodynamic consequences of barnacle colonization. Hydrobiologia 375/376:191-201

Turner SJ, Todd CD (1993) The early development of epifaunal assemblages on artificial substrata at two intertidal sites on an exposed rocky shore in St Andrews Bay, N.E. Scotland. J Exp Mar Biol Ecol 166:251-272

Weatherby AJ, Warren PH, Law R (1998) Coexistence and collapse: an experimental investigation of the persistent communities of a protist species pool. J Anim Ecol 67: $554-566$

Weiher E, Keddy PA (1995) The assembly of experimental wetland plant-communities. Oikos 73:323-335

Wieczorek SK, Todd CD (1997) Inhibition and facilitation of bryozoan and ascidian settlement by natural multi-species biofilms: effects of film age and the roles of active and passive larval attachment. Mar Biol 128:463-473

Wieczorek SK, Murray AWA, Todd CD (1996) Seasonal variation in the effects of hard substratum biofilming on settlement of marine invertebrate larvae. Biofouling 10: 309-330

Wilson JB, Gitay H (1995) Community structure and assembly rules in a dune slack - variance in richness, guild proportionality, biomass constancy and dominance/diversity relations. Vegetatio 116:93-106

Zar JH (1999) Biostatistical analysis, 4th edn. Prentice-Hall, Upper Saddle River, NJ

Submitted: March 15, 2005; Accepted: August 20, 2005

Proofs received from author(s): December 14, 2005 